\title{
GABAergic transmission in rat pontine reticular formation regulates the induction phase of anesthesia and modulates hyperalgesia caused by sleep deprivation
}

\author{
Giancarlo Vanini, Kriste Nemanis, Helen A. Baghdoyan and Ralph Lydic \\ Department of Anesthesiology, University of Michigan, 7433 Medical Science Building I, 1150 West Medical Center Drive, Ann \\ Arbor, Ml 48109-5615, USA
}

Keywords: consciousness, emergence, microdialysis, microinjection, pain

\begin{abstract}
The oral part of the pontine reticular formation $(\mathrm{PnO})$ contributes to the regulation of sleep, anesthesia and pain. The role of PnO $\gamma$-aminobutyric acid (GABA) in modulating these states remains incompletely understood. The present study used time to loss and time to resumption of righting response (LoRR and RoRR) as surrogate measures of loss and resumption of consciousness. This study tested three hypotheses: (i) pharmacologically manipulating GABA levels in rat PnO alters LoRR, RoRR and nociception; (ii) propofol decreases GABA levels in the PnO; and (iii) inhibiting GABA synthesis in the PnO blocks hyperalgesia caused by sleep deprivation. Administering a GABA synthesis inhibitor [3-mercaptopropionic acid (3-MPA)] or a GABA uptake inhibitor [nipecotic acid (NPA)] into rat PnO significantly altered LoRR caused by propofol. 3-MPA significantly decreased LoRR for propofol $(-18 \%)$. NPA significantly increased LoRR during administration of propofol $(36 \%)$. Neither 3-MPA nor NPA altered RoRR following cessation of propofol or isoflurane delivery. The finding that LoRR was decreased by 3-MPA and increased by NPA is consistent with measures showing that extracellular GABA levels in the PnO were decreased $(41 \%)$ by propofol. Thermal nociception was significantly decreased by 3-MPA and increased by NPA, and 3-MPA blocked the hyperalgesia caused by sleep deprivation. The results demonstrate that GABA levels in the PnO regulate the time for loss of consciousness caused by propofol, extend the concept that anesthetic induction and emergence are not inverse processes, and suggest that GABAergic transmission in the PnO mediates hyperalgesia caused by sleep loss.
\end{abstract}

\section{Introduction}

$\gamma$-Aminobutyric acid (GABA)-mediated transmission participates in regulating the three interacting states of sleep (Brown et al., 2012), anesthesia (Brown et al., 2010) and pain (Enna \& McCarson, 2006). Drugs that enhance transmission at $\mathrm{GABA}_{\mathrm{A}}$ receptors are used clinically as sedative-hypnotics (Richey \& Krystal, 2011) and general anesthetics (Franks, 2008; Brown et al., 2010). The GABA analogs pregabalin and gabapentin that are prescribed to treat chronic pain cause analgesia, in part, by increasing ambient levels of GABA (Maneuf et al., 2003; Tassone et al., 2007). Efforts to identify the mechanisms through which GABAergic transmission so powerfully modulates states of arousal and pain must contend with the fact that the effects of GABAergic transmission vary by brain region (Baghdoyan \& Lydic, 2012; Vanini et al., 2012).

In the oral part of the pontine reticular formation $(\mathrm{PnO})$, GABAergic transmission contributes to the regulation of sleep and wakefulness (reviewed in Steriade \& McCarley, 2005; Brown et al., 2010). Pharmacologically enhancing GABAergic transmission in the $\mathrm{PnO}$ increases wakefulness and decreases sleep (Watson et al.,

Correspondence: Dr G. Vanini, as above.

E-mail: gvanini@umich.edu

Received 30 October 2013, revised 19 February 2014, accepted 21 February 2014
2008; Flint et al., 2010; Vanini et al., 2011; Vanini \& Baghdoyan, 2013). Similarly, administration of drugs that decrease GABAergic transmission in the $\mathrm{PnO}$ decreases wakefulness and increases sleep (Marks et al., 2008; Watson et al., 2008; Flint et al., 2010).

The findings that increasing GABA levels in the PnO promotes wakefulness and decreasing GABA levels in the PnO promotes sleep (Watson et al., 2008) are consistent with parallel studies using the general anesthetic isoflurane (Vanini et al., 2008). The isoflurane studies showed that administering a GABA synthesis inhibitor into the PnO to decrease GABA levels caused a decrease in anesthetic induction time, and increasing GABA levels in the $\mathrm{PnO}$ with a GABA uptake inhibitor caused an increase in isoflurane induction time (Vanini et al., 2008). The foregoing data raised the questions of whether manipulating GABA levels in the PnO: (i) alters the time to recovery from anesthesia caused by isoflurane; and (ii) modulates the time required for anesthetic induction and recovery of wakefulness for non-inhaled anesthetics.

The present experiments were designed to test three hypotheses that share the unifying goal of identifying brain regions and neurotransmitters regulating interacting states of arousal and pain. The first hypothesis was that manipulating GABA levels in the PnO alters recovery time from isoflurane anesthesia, induction and recovery time for the intravenous anesthetic propofol, and nociception. 
These experiments blocked GABA synthesis or GABA uptake while quantifying time to loss of righting response (LoRR), time to resumption of righting response (RoRR), and paw withdrawal latency (PWL) in response to a thermal stimulus. The second hypothesis was that propofol decreases extracellular GABA levels in the PnO. The third hypothesis was that hyperalgesia caused by sleep deprivation (Arima et al., 2001; Edwards et al., 2008; Roehrs et al., 2012) is diminished by administration of a GABA synthesis inhibitor into the PnO. Preliminary reports from these experiments have appeared as abstracts (Vanini et al., 2009; Nemanis et al., 2011; Vanini \& Nemanis, 2013).

\section{Materials and methods}

\section{Animals, chemical suppliers and drug solutions}

All procedures using rats were approved by the University Committee on Use and Care of Animals, and followed the Guide for the Care and Use of Laboratory Animals (National Academies Press, 8th Edition, Washington, DC, 2011). Adult (250-350 g) male Sprague-Dawley rats $(n=39)$ were purchased from Charles River Laboratories, Wilmington, MA, USA. Animals were housed in a 12-h light : dark cycle within the Unit for Laboratory Animal Medicine facility. Rats had free access to food and water. The GABA uptake inhibitor nipecotic acid (NPA; Krogsgaard-Larsen \& Johnston, 1975), the GABA synthesis inhibitor 3-mercaptopropionic acid (3-MPA; Engel et al., 2001), high-performance liquid chromatography (HPLC)-grade methanol, acetonitrile, sodium tetraborate decahydrate, B-mercaptoethanol and GABA were purchased from Sigma-Aldrich (St Louis, MO, USA). The supplier for salts used to make Ringer's solution (in mM: NaCl, 147.0; $\mathrm{CaCl}_{2}$, 2.4; $\mathrm{KCl}, 4.0 ; \mathrm{MgSO}_{4}, 1.0 ; \mathrm{pH} 6.0$ ), o-phosphoric acid and sodium phosphate dibasic was Thermo Fisher Scientific (Waltham, MA, USA). $o$-Phthaldialdehyde was purchased from Mallinckrodt (St Louis, MO, USA). Propofol (1\%) was obtained from APP Pharmaceuticals, LLC (Schamburg, IL, USA). NPA $(1.29 \mu \mathrm{g} / 100 \mathrm{~nL}$; $10 \mathrm{nmol})$ and 3-MPA $(1.06 \mu \mathrm{g} / 100 \mathrm{~nL} ; 10 \mathrm{nmol})$ were dissolved and diluted in Ringer's solution immediately before each experiment.

\section{Surgical procedures and conditioning}

Rats were anesthetized with $3.0 \%$ isoflurane (Hospira, Lake Forest, IL, USA) in $100 \% \mathrm{O}_{2}$. The delivered concentration of isoflurane was measured continuously by spectrometry (Cardiocap $^{\mathrm{TM}} / 5$; DatexOhmeda, Louisville, CO, USA). When anesthetized, rats were placed in a Kopf Model 962 stereotaxic frame fitted with a Model 906 rat anesthesia mask (David Kopf Instruments, Tujunga, CA, USA). The delivered isoflurane concentration was then reduced to $2.0 \%$. The core body temperature was maintained at $37-38{ }^{\circ} \mathrm{C}$ using a water-filled pad connected to a heat pump (Gaymar Industries, Orchard Park, NY, USA). The skull was exposed and a microinjection guide cannula (C313G2UP22; Plastics One, Roanoke, VA, USA) was aimed $3 \mathrm{~mm}$ above the $\mathrm{PnO}$ at stereotaxic coordinates: $8.4 \mathrm{~mm}$ posterior to bregma; $1.0 \mathrm{~mm}$ lateral to the midline; and $6.2 \mathrm{~mm}$ below the skull surface (Paxinos \& Watson, 2007). For microdialysis experiments, one CMA/11 guide cannula (CMA, North Chelmsford, MA, USA) was aimed $1 \mathrm{~mm}$ above the $\mathrm{PnO}$ at $8.4 \mathrm{~mm}$ posterior to bregma, $1.0 \mathrm{~mm}$ lateral to bregma and $8.4 \mathrm{~mm}$ ventral to the skull surface (Paxinos \& Watson, 2007). The microinjection or microdialysis guide cannula and six anchor screws (MPX008002PC; Small Parts, Miami Lakes, FL, USA) were fixed to the skull with dental acrylic (Lang Dental Manufacturing Company, Wheeling, IL, USA).

A second group of rats also was implanted with jugular vein catheters in order to administer propofol during subsequent microinjection or microdialysis experiments. A silicone catheter $\left(0.020^{\prime \prime} \times 0.037 " \times 0.0065^{\prime \prime}\right.$; Dow Corning, Midland, MI, USA $)$ was inserted into the external jugular vein, sutured and tunneled subcutaneously to exit between the scapulae, as described previously (Hambrecht-Wiedbusch et al., 2010; Gauthier et al., 2011). The catheter pedestal held a $22 \mathrm{G}$ cannula (C313G3UPSPC; Plastics One, Roanoke, VA, USA) cemented with dental acrylic to a piece of polyethylene mesh (Robinson et al., 2001). Intravenous infusion of $0.2 \mathrm{~mL}$ sterile heparin-saline solution $(100 \mathrm{U} / \mathrm{mL})$ was performed daily to maintain patent catheters.

All rats received a single dose of gentamicin $(5 \mathrm{mg} / \mathrm{kg}$, intravenous), and analgesia was maintained with carprofen $(5 \mathrm{mg} / \mathrm{kg}$, subcutaneous) for a minimum of $24 \mathrm{~h}$ after surgery. Rats were given 1 week to recover from surgery, during which time they were conditioned to handling that simulated procedures for intracerebral microinjections. Rats implanted for microdialysis were conditioned to a Raturn ${ }^{\circledR}$ recording chamber [Bioanalytical Systems (BAS), West Lafayette, IN, USA] for 1 week before being used for an experiment. Rats used for nociceptive testing were conditioned to the IITC Model 336T Paw Stimulator Analgesia Meter with a heated glass plate (IITC Model 400 Heated Base; IITC Life Science, CA, USA). In all experiments, microinjections of Ringer's solution and drug $(100 \mathrm{~nL})$ into the same rat were made in random order and were separated by 7 days. A microinjection volume of $100 \mathrm{~nL}$ is estimated to spread up to $0.8-1 \mathrm{~mm}$ in diameter within the first hour post-injection (Vanini et al., 2007).

\section{Study design and procedures}

\section{Quantification of recovery time from isoflurane anesthesia}

LoRR and RoRR are widely used in rodents as surrogate measures of loss and resumption of consciousness, respectively (Tung et al., 2005; Alkire et al., 2007; Franks, 2008; Vanini et al., 2008; Hudetz et al., 2011). Figure $1 \mathrm{~A}$ illustrates the experimental design used to quantify time to RoRR after discontinuation of isoflurane delivery. All studies began at approximately the same time each day (between 13:00 and 14:00 h). After a 5-min period (Fig. $1 \mathrm{~A} ; t=-10 \mathrm{~min}$ ) of acclimation to the induction chamber, $1.5 \%$ isoflurane in oxygen was delivered at $2 \mathrm{~L} / \mathrm{min}$. After induction (Fig. $1 \mathrm{~A} ; t=0 \mathrm{~min}$ ), rats were fitted with an anesthesia mask, the oxygen flow rate was reduced to $0.5 \mathrm{~L} / \mathrm{min}$ and the concentration of delivered isoflurane was maintained at $1.5 \%$. Fourteen minutes after the LoRR, Ringer's solution (vehicle control), NPA or 3-MPA was microinjected into the PnO. The injection duration was $1 \mathrm{~min}$ (Fig. $1 \mathrm{~A} ; t=14$ to $t=15 \mathrm{~min}$ ). Isoflurane administration was discontinued $15 \mathrm{~min}$ after the end of the microinjection (Fig. 1A; $t=30 \mathrm{~min}$; total anesthesia time $=30 \mathrm{~min}$ ). Upon cessation of isoflurane delivery, the anesthesia mask was removed and rats were placed in a supine position. RoRR was quantified as the time (min) from cessation of isoflurane administration to resumption of a prone position. The core body temperature was maintained in all experiments during anesthesia as described above.

\section{Quantification of induction time with propofol}

After a 10-min acclimation period to a Plexiglas chamber, Ringer's solution, NPA or 3-MPA was microinjected (Fig. 1B; $t=0$ min) into the PnO. Fifteen minutes after microinjection, induction of 
A Timeline for quantifying RoRR with isoflurane

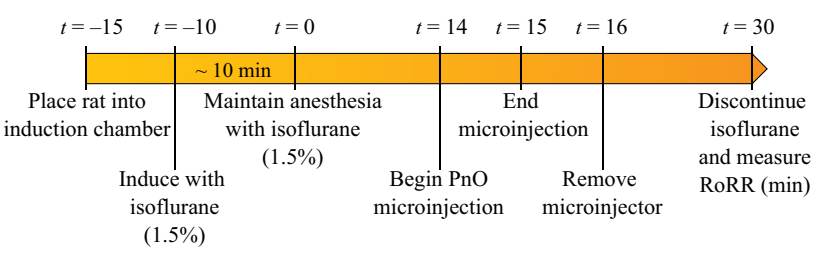

B Timeline for quantifying LoRR with propofol

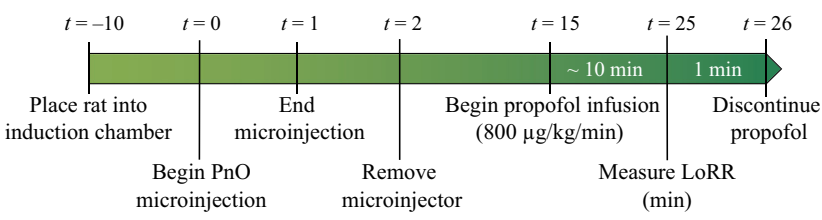

C Timeline for quantifying RoRR with propofol

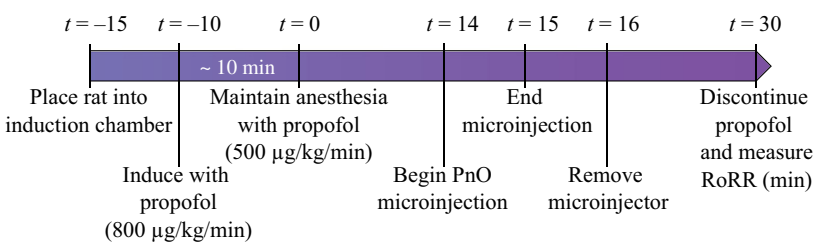

FIG. 1. Timelines for quantifying changes in recovery and induction time caused by manipulating GABA levels in the pontine reticular nucleus, oral part $(\mathrm{PnO})$. Elapsed time $(t)$ in minutes is indicated above each timeline. After induction of anesthesia with isoflurane (A), rats received a microinjection of Ringer's solution (vehicle control), NPA or 3-MPA into the PnO. Anesthesia was maintained for $30 \mathrm{~min}$ after induction. Isoflurane delivery then was discontinued, rats were placed in a supine position, and recovery from anesthesia was quantified as the time to resumption of righting response (RoRR). For quantification of induction time with propofol (B), rats received a microinjection of Ringer's solution or drug (NPA or 3-MPA) during wakefulness. Fifteen minutes after the end of the microinjection, continuous intravenous infusion of propofol began and the time to induction was quantified as the time to loss of righting response (LoRR). For quantification of recovery time after propofol anesthesia (C), the timeline and procedures were the same as in the isoflurane experiments.

anesthesia began (Fig. 1B; $t=15 \mathrm{~min}$ ) by continuous intravenous administration of propofol $(800 \mu \mathrm{g} / \mathrm{kg} / \mathrm{min})$. The induction time was quantified as the time (min) to LoRR.

\section{Quantification of recovery time from propofol anesthesia}

Rats were conditioned to a Plexiglas induction chamber (Fig. 1C; $t=-15 \mathrm{~min}$ ) prior to induction of anesthesia by continuous administration of propofol $(800 \mu \mathrm{g} / \mathrm{kg} / \mathrm{min})$. Propofol was delivered using a CMA/400 syringe pump (CMA, North Chelmsford, MA, USA) connected to the implanted intravenous line (Fig. 1C; $t=-10 \mathrm{~min}$ ). For all experiments using propofol, rats remained in a Plexiglas chamber during periods of induction, maintenance and emergence. After induction of anesthesia (Fig. 1C; $t=0 \mathrm{~min}$ ), propofol flow rate was reduced $(500 \mu \mathrm{g} / \mathrm{kg} / \mathrm{min})$ and maintained for $30 \mathrm{~min}$ to ensure that the concentration of propofol in the brain had equilibrated (Dutta et al., 1997). As illustrated in Fig. 1C, 14 min after propofol-induced loss of consciousness, each rat received a microinjection of Ringer's solution, NPA or 3-MPA into the PnO (Fig. 1C; $t=14$ to $t=15 \mathrm{~min}$ ). Fifteen minutes after the microinjection, intravenous propofol delivery was discontinued (Fig. 1C; $t=30 \mathrm{~min}$ ) and rats were placed in a dorsal recumbent position. Recovery time (min) was quantified by measuring the time to RoRR.
In vivo microdialysis, intravenous propofol administration and quantification of $\mathrm{PnO}$ GABA levels

Each rat was used for only one microdialysis experiment. A CMA/11 microdialysis probe (cuprophane membrane with a $1 \mathrm{~mm}$ length, $0.24 \mathrm{~mm}$ diameter and $6 \mathrm{kDa}$ cut-off) was aimed at the PnO and perfused with Ringer's solution at a flow rate of $2.0 \mu \mathrm{L} / \mathrm{min}$ using a CMA/400 syringe pump. Microdialysis sample collection $(14 \mu \mathrm{L})$ began $1 \mathrm{~h}$ after probe insertion to allow extracellular GABA levels to stabilize (Watson et al., 2008). Each experiment consisted of collecting five sequential samples during wakefulness followed by five samples during anesthesia. Procedures and doses for anesthesia with propofol were the same as described above for determining time to LoRR and RoRR. Samples were collected on ice for subsequent quantification of GABA. The amount of GABA recovered by each dialysis probe in vitro was calculated before and after each experiment. Mean \pm SEM recovery for all the probes used was $6.7 \pm 0.5 \%$.

The methods used to quantify extracellular GABA levels have been described previously (Vanini et al., 2008, 2011, 2012). Briefly, dialysis samples obtained from the PnO were analysed using an ESA HPLC system (Chelmsford, MA, USA) and EZChrom Elite chromatography data system (Scientific Software, Pleasanton, CA, USA). Each sample was mixed in an autosampler with a derivatization solution (o-phthaldialdehyde, $\beta$-mercaptoethanol, borate buffer and methanol), and then injected into a Shiseido CAPCELL PAK C-18 separation column (JM Science, Grand Island, NY, USA). The detection limit for GABA was $11 \mathrm{fmol} / 10 \mu \mathrm{L}$. Standard curves were generated before and after each experiment, and were used to calculate the amount of GABA in each sample and to ensure that the sensitivity of the detection system remained unchanged during the analysis.

\section{Nociceptive testing, sleep deprivation and $\mathrm{PnO}$ drug administration}

Effects of drugs and arousal state on thermal nociception were measured using the Hargreaves' PWL method (Hargreaves et al., 1988). To test for nociception, a thermal light source was focused onto the plantar surface of a hind paw and then activated. The light was then switched from idle to active intensity (40\%), and a timer was simultaneously activated with onset of the thermal stimulus. The rat responded by moving its paw away from the stimulus. Immediately upon paw withdrawal, the thermal source and the timer were deactivated and the latency to withdrawal in seconds was recorded. On experiment days, rats were habituated to the individual experiment chambers for $20 \mathrm{~min}$ prior to testing. Immediately after the habituation period, baseline PWL was determined by five measurements taken over $20 \mathrm{~min}$. These five measurements were averaged for each animal to obtain the baseline latency.

These experiments quantified whether nociception was increased or decreased, respectively, by $\mathrm{PnO}$ administration of a drug that inhibits GABA uptake (NPA) or a drug that decreases GABA synthesis (3-MPA). Rats received, in random order, a microinjection of Ringer's solution (vehicle), 3-MPA or NPA. Thereafter, four PWL measurements were taken at 20,30,60, 90 and 120 min post-microinjection and averaged for each time point.

Additional experiments determined whether hyperalgesia caused by sleep deprivation was diminished by $\mathrm{PnO}$ administration of a GABA synthesis inhibitor (3-MPA). Rats received a microinjection of: (i) Ringer's solution and were allowed to sleep ad libitum during the intervals between PWL measurements; (ii) Ringer's solution and were sleep deprived by gentle handling (Tobler \& Jaggi, 1987; Baracchi \& Opp, 2008; Peterfi et al., 2010) during 4 h of PWL testing; or (iii) 3-MPA and were sleep deprived during $4 \mathrm{~h}$ of PWL testing. 
After the microinjection, four PWL measurements were taken at 20, $30,60,90,120,150,180,210$ and 240 min post-microinjection.

All PWL measurements were obtained using bilateral stimulation by alternating the noxious thermal stimulus between right and left hind paws. Each experiment in the same rat was separated by a minimum of 5 days. The latency in seconds to paw withdrawal in response to the stimulus was expressed as a percentage change from pre-microinjection baseline values [percentage of maximum possible effect (\%MPE); Hayes et al., 1984] using the following equation: \% $\mathrm{MPE}=($ post-injection PWL - baseline PWL $) /($ cut-off time - baseline $\mathrm{PWL}) \times 100$. A cut-off time of $15 \mathrm{~s}$ for the thermal stimulus was used to ensure no tissue damage. Positive \%MPE values indicate a longer latency to paw withdrawal in response to the stimulus relative to baseline measures, consistent with decreased nociception. Negative \%MPE values indicate shorter PWLs that are consistent with increased nociception.

\section{Histological localization of microinjection and microdialysis sites}

Upon completion of the experiments, animals were deeply anesthetized with isoflurane and decapitated. Brains were removed, frozen and sectioned coronally at $40 \mu \mathrm{m}$. All tissue sections containing the pontine reticular formation were mounted serially on glass slides, dried, fixed with hot paraformaldehyde vapor, and stained with Cresyl violet. Sections containing microinjection or microdialysis sites were digitized, and stereotaxic coordinates of microinjection and microdialysis sites were defined by comparison with a rat brain atlas (Paxinos \& Watson, 2007).

\section{Statistical analysis}

Statistical evaluation of the data was performed with input from the University of Michigan Center for Statistical Consultation and Research. Data analyses were performed using Statistical Analysis System (SAS) version 9.2 (SAS Institute, Cary, NC, USA) and PRISM v6.0c for Mac OS X (GraphPad Software, La Jolla, CA, USA). All data were tested for normality. Data are reported as mean \pm SEM, and a $P$-value $<0.05$ was considered statistically significant.

\section{Induction of and recovery from anesthesia}

Because the data did not meet the assumptions of the underlying general linear model (i.e. normality was rejected), drug effects on LoRR and RoRR were evaluated by non-parametric statistics using Wilcoxon matched-pairs signed-rank tests. In addition, the magnitude of the treatment effect (effect-size) for the time to induction with propofol and isoflurane was quantified by computing Cohen's $d$ for each measure.

\section{GABA measurement}

GABA levels are reported as either fmol/10 $\mu \mathrm{L}$ or normalized as percentage change from average GABA levels during wakefulness (control). The differences in GABA levels as a function of arousal state were assessed by a linear mixed model allowing a random effect by rat and by condition nested within rat.

\section{Nociception}

Differences in \%MPE (thermal nociception) as a function of time, drug, and time by drug interaction were evaluated by repeated-measures, two-way ANOVA using a linear mixed model, controlling for random effects due to rat and experiment. Post hoc Tukey-Kramer procedure and $t$-test adjusted for multiple comparisons were used to evaluate differences in mean \%MPE per time point. A mixed model was used to analyse changes in \%MPE as a function of time and drug during sleep deprivation, allowing random intercepts and slopes per animal within each experiment. The differences in mean $\%$ MPE were determined by paired $t$-test or Kruskal-Wallis test and post hoc Dunn's test.

\section{Results}

Inhibiting GABA synthesis and GABA uptake in the PnO altered induction time but did not change recovery time

\section{Isoflurane}

Previously published data showed that microinjection of the GABA synthesis inhibitor 3-MPA into the PnO significantly decreased LoRR caused by isoflurane (Vanini et al., 2008). Consistent with evidence that GABAergic transmission in the pontine reticular formation promotes wakefulness (Vanini et al., 2011; Vanini \& Baghdoyan, 2013), administration of the GABA uptake inhibitor NPA into the PnO increased LoRR with isoflurane (Vanini et al., 2008).

In contrast, Fig. 2 illustrates that microinjection of the GABA synthesis inhibitor, 3-MPA ( $n=9$ rats) and the GABA reuptake inhibitor, NPA ( $n=10$ rats) into the PnO did not significantly alter RoRR after isoflurane anesthesia. In order to achieve statistical power for detecting a significant difference in time to recovery from
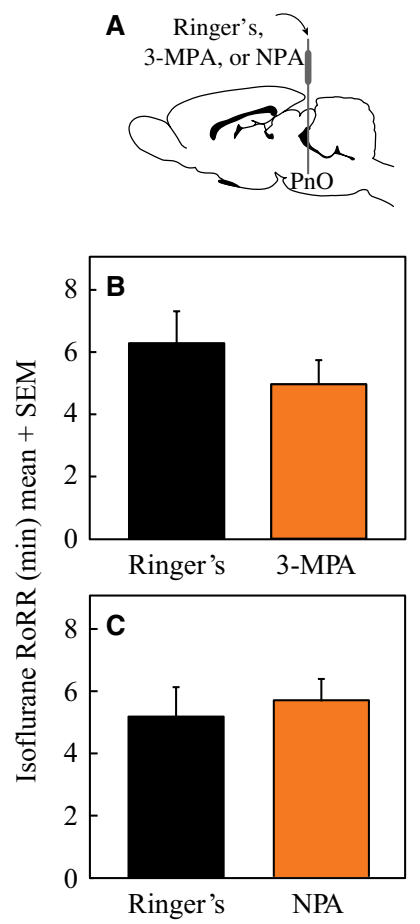

FIG. 2. Pharmacologically increasing or decreasing endogenous GABA levels in the pontine reticular nucleus, oral part $(\mathrm{PnO})$ did not alter recovery time. A schematic sagittal view of the rat brain illustrates that a cannula inserted into the $\mathrm{PnO}$ was used for microinjection of Ringer's solution or drug (A). Microinjection of either the GABA synthesis inhibitor 3-mercaptopropionic acid (3-MPA) (B) or the GABA uptake inhibitor nipecotic acid (NPA) (C) into the $\mathrm{PnO}$ did not alter the time to resumption of righting response (RoRR) after isoflurane anesthesia. 
isoflurane anesthesia, power calculations indicate that a minimum of 38 and 462 rats would be required for 3-MPA and NPA, respectively.

\section{Propofol}

Figure 3 summarizes the effects of 3-MPA and NPA on induction and recovery time caused by propofol. Microinjection of the GABA synthesis inhibitor 3-MPA ( $n=6$ rats) into the PnO significantly $(P=0.03)$ decreased LoRR caused by propofol (Fig. 3A). The GABA uptake inhibitor NPA $(n=5$ rats) significantly $(P=0.03)$ increased LoRR (Fig. 3B). Calculation of Cohen's $d$ revealed a large treatment effect on propofol-induced LoRR for both 3-MPA $(d=0.8)$ and NPA $(d=1.1)$. Also consistent with the results obtained with isoflurane was the finding that microinjection of 3-MPA ( $n=7$ rats; Fig. 3C) and NPA ( $n=7$ rats; Fig. 3D) had no effect on RoRR after propofol anesthesia. Power calculations indicate that a minimum of 705 and 129 rats would be needed for the effects of 3-MPA and NPA, respectively, to achieve statistical power for detecting a significant difference in the time to recovery from propofol anesthesia.

Figure $3 \mathrm{E}$ and $\mathrm{F}$ plotted mean extracellular GABA levels in the $\mathrm{PnO}$ during states of wakefulness and anesthesia with propofol. Relative to wakefulness, propofol caused a significant $(F=75.68$; $\mathrm{df}=1,2 ; P=0.013)$ decrease $(41 \%)$ in GABA levels. The graphs plot GABA levels averaged across experiments for all rats $(n=3)$.
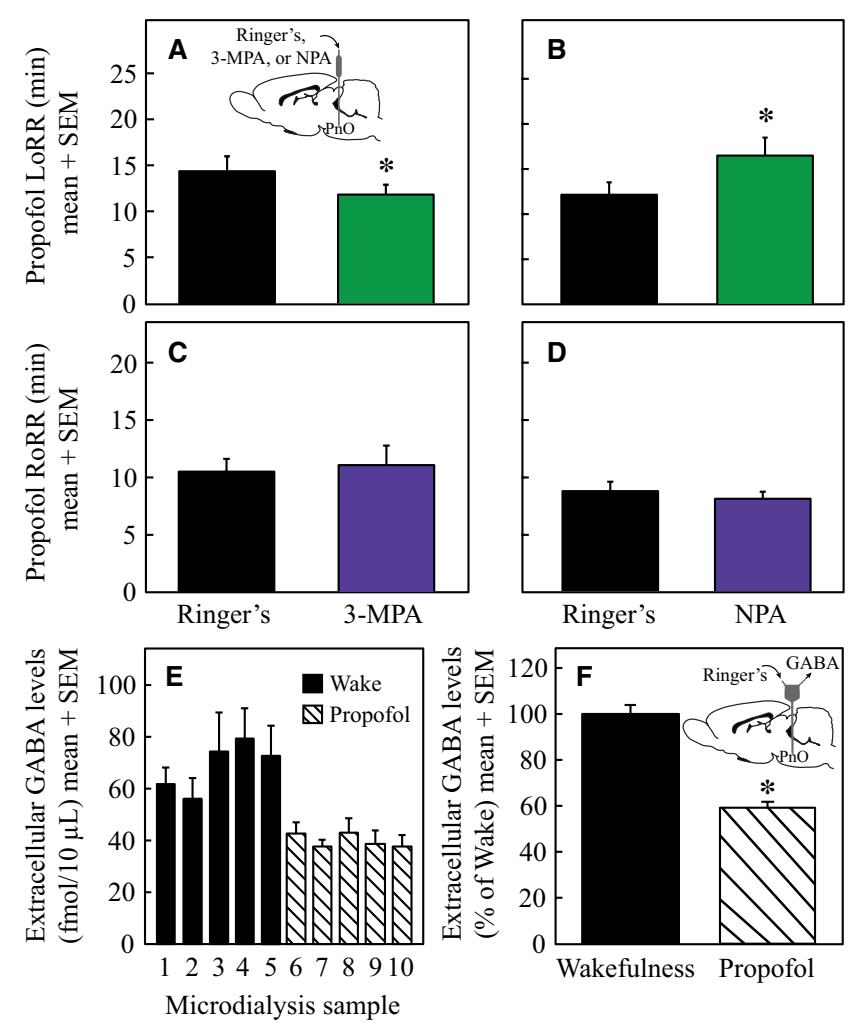

FIG. 3. Pharmacologically increasing or decreasing endogenous $\gamma$-aminobutyric acid (GABA) levels in the pontine reticular nucleus, oral part $(\mathrm{PnO})$ altered propofol induction time but not recovery time. Administration of 3mercaptopropionic acid (3-MPA) and nipecotic acid (NPA) into the PnO significantly decreased (A) or increased (B), respectively, the time to loss of righting response (LoRR). In contrast, 3-MPA (C) and NPA (D) had no effect on the time to resumption of righting response (RoRR) after propofol anesthesia. Relative to wakefulness, extracellular GABA levels in the PnO were significantly decreased (E and $\mathrm{F}$ ) during anesthesia with propofol.
Figure 4A shows that microinjection sites from the isoflurane studies were all localized to the $\mathrm{PnO}$, with average stereotaxic coordinates $-8.0 \pm 0.1 \mathrm{~mm}$ from bregma, $0.8 \pm 0.2 \mathrm{~mm}$ from the midline and $-8.3 \pm 0.1 \mathrm{~mm}$ from the skull surface (Paxinos \& Watson, 2007). All microinjection sites for studies that measured time to induction and recovery from propofol anesthesia were localized to the $\mathrm{PnO}$ (Fig. 4B). Average PnO stereotaxic coordinates for Fig. 4B data were $-8.3 \pm 0.1 \mathrm{~mm}$ from bregma, $1.2 \pm 0.1 \mathrm{~mm}$ from midline and $-8.5 \pm 0.1 \mathrm{~mm}$ from the skull surface (Paxinos \& Watson, 2007). Histological analysis confirmed that all measures of extracellular GABA levels were obtained from the PnO (Fig. 4C).

\section{Inhibition of GABA synthesis and GABA uptake mechanisms in the PnO altered thermal nociception}

Figure 5A shows that the GABA synthesis inhibitor 3-MPA significantly $(t=5.818 ;$ df $=24 ; P<0.0001)$ decreased thermal

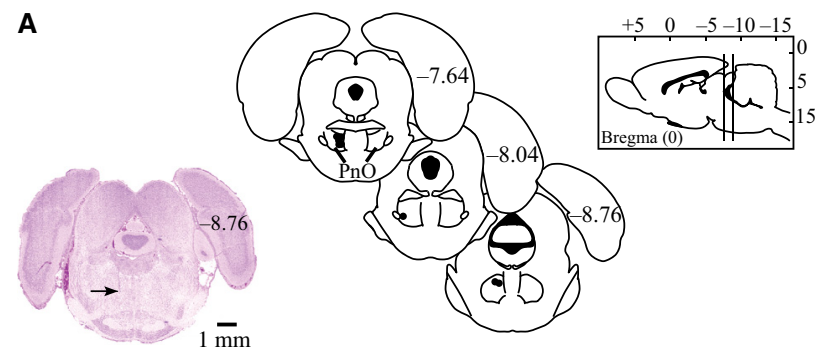

B


FIG. 4. Microinjection and microdialysis sites were localized to the oral pontine reticular nucleus $(\mathrm{PnO})$. The sagittal drawing of the rat brain (top right) contains vertical lines that illustrate the anterior-to-posterior range of all microinjection and microdialysis sites. Microinjection sites from the isoflurane study (A) and the propofol study (B) are represented by black dots on coronal schematics modified from a rat brain atlas (Paxinos \& Watson, 2007). Numbers on the right side of each schematic indicate $\mathrm{mm}$ posterior to bregma. The tissue sections at the bottom left of (A) and (B) show representative brain stem sections stained with Cresyl violet. Arrows on each section indicate a microinjection site in the left PnO. Coronal schematics (C) of rat brain stem modified from a rat brain atlas (Paxinos \& Watson, 2007) show the location of each microdialysis membrane, drawn to scale as gray cylinders. Histological analysis also confirmed that GABA measures were obtained from the PnO. The coronal stained section to the right shows a representative microdialysis site in the right $\mathrm{PnO}$. The arrow indicates the deepest portion of the microdialysis site. 

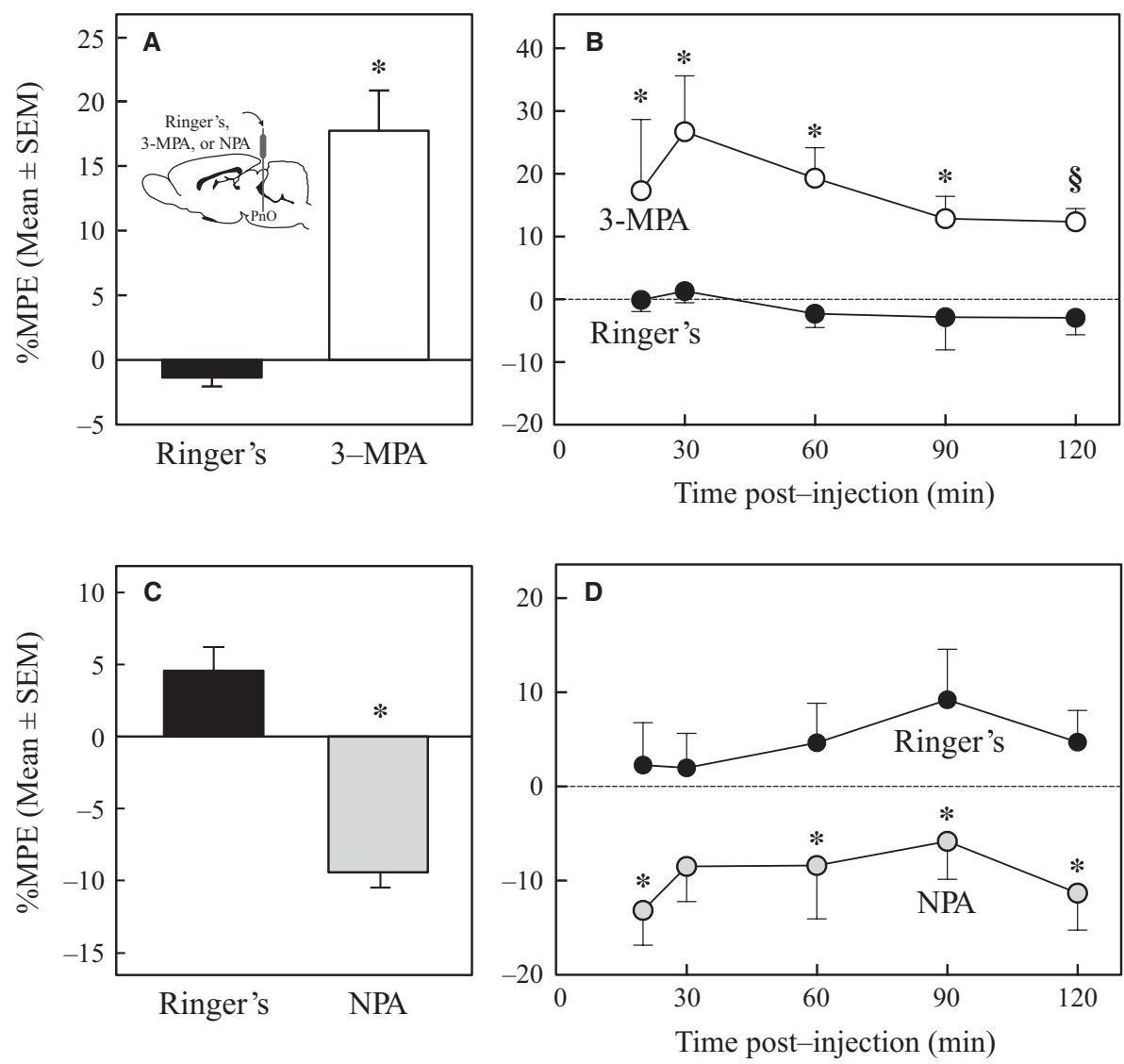

FIG. 5. Pharmacologically increasing or decreasing endogenous GABA levels in the pontine reticular nucleus, oral part (PnO) altered thermal nociception. Microinjection of the GABA synthesis inhibitor 3-mercaptopropionic acid (3-MPA) significantly increased the percentage of maximum possible effect (\%MPE), reflecting decreased thermal nociception (A). (B) Time course of thermal nociception during $2 \mathrm{~h}$ after a microinjection of 3-MPA. Administration of the GABA uptake inhibitor nipecotic acid (NPA) significantly decreased \%MPE, indicating increased thermal nociception (C). (D) Time course of the effect on thermal nociception during $2 \mathrm{~h}$ after microinjection of NPA. Time 0 on the abscissa indicates the end of the 1-min period during which Ringer's solution or drug was microinjected into the PnO. Asterisks (*) indicate significant differences from control (Ringer's solution). The $\S$ symbol in (B) indicates $P=0.0545$.

nociception (i.e. increased \%MPE). The graph plots \%MPE averaged across the 2 -h testing session for all rats $(n=5)$. Figure $5 \mathrm{~B}$ illustrates the time course of \%MPE during $2 \mathrm{~h}$ after microinjection of 3-MPA. ANOVA revealed a significant $(F=11.49$; df $=1,8$; $P=0.0095)$ drug effect. Figure 5C summarizes the effect of PnO administration of a GABA uptake inhibitor. NPA significantly $(t=5.650 ; \mathrm{df}=39 ; P<0.0001)$ increased thermal nociception (i.e. decreased \%MPE). The graph plots \%MPE collapsed across time for all rats $(n=8)$. Figure 5D shows the time course data during $2 \mathrm{~h}$ post-microinjection. ANOva revealed a significant $(F=8.72$; $\mathrm{df}=1,14 ; P=0.0105)$ main drug effect.

\section{Administration of a GABA synthesis inhibitor into the PnO decreased hyperalgesia caused by sleep deprivation}

Figure 6A shows that, relative to control, sleep deprivation significantly $(P=0.0080)$ decreased \%MPE (i.e. increased thermal nociception). Administration of 3-MPA into the PnO before the onset of sleep deprivation significantly $(P<0.0001)$ increased \%MPE over control levels, preventing the hyperalgesia caused by sleep deprivation. The time course of \%MPE during $4 \mathrm{~h}$ as a function of drug, sleep and time after $\mathrm{PnO}$ microinjection is shown in Fig. 6B. Repeated-measures, two-way ANOvA indicated a significant $(F=6.04 ;$ df $=2,18 ; P=0.0098)$ effect of treatment (i.e. sleep deprivation and sleep deprivation plus 3-MPA). There was no post-injection time effect, or treatment condition by time interaction. Post hoc tests revealed a significant increase in \%MPE caused by 3MPA. Regression analysis of \%MPE after PnO microinjection of Ringer's solution revealed that there was a significant $(P=0.0033)$ linear increase in thermal nociception during $4 \mathrm{~h}$ of sleep deprivation. The time spent awake accounted for a significant percentage (76\%) of the variance in \%MPE. The data shown in Fig. 6 summarize the results from seven rats that received all three treatments. Microinjection sites from all pain studies (Figs 5 and 6) were localized within the $\mathrm{PnO}$ (Fig. 7), at average stereotaxic coordinates $-8.3 \pm 0.1 \mathrm{~mm}$ from bregma, $1.2 \pm 0.1 \mathrm{~mm}$ from the midline and $-8.5 \pm 0.1 \mathrm{~mm}$ from the skull surface (Paxinos \& Watson, 2007).

\section{Discussion}

The present data show that the time to LoRR, but not time to RoRR, caused by both isoflurane and propofol was significantly altered by manipulating GABA levels in the PnO. These results provide novel evidence that GABA in the PnO promotes wakefulness, and demonstrate in rat that induction of and emergence from anesthesia are not inverse processes. The present data extend previous findings (Kelz et al., 2008) by showing that the induction and emergence phases of anesthesia are differentially regulated by a specific brain region $(\mathrm{PnO})$ and neurotransmitter (GABA). Measures of extracellular GABA levels during wakefulness and anesthesia 

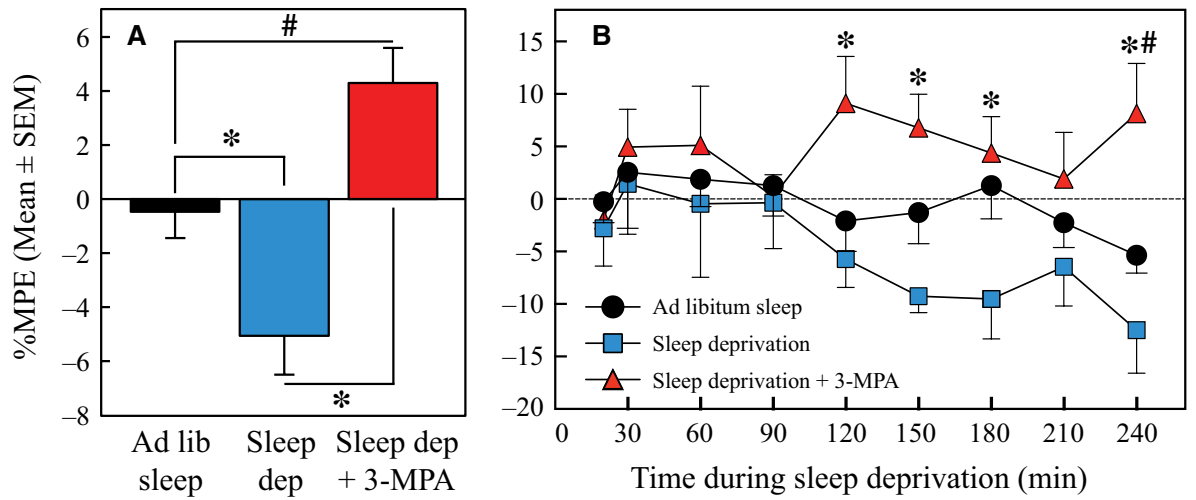

FIG. 6. Microinjection of a GABA synthesis inhibitor into the rat PnO reversed the hyperalgesia caused by sleep deprivation. (A) Sleep deprivation significantly decreased the percentage of maximum possible effect (\%MPE; i.e. increased thermal nociception). PnO administration of 3-mercaptopropionic acid (3MPA) significantly increased \%MPE, preventing the increase in nociception caused by sleep deprivation. (B) Time course of \% MPE during $4 \mathrm{~h}$ as a function of drug, sleep and time after PnO microinjection. Administration of 3-MPA caused a significant increase in \% MPE during the 4-h testing period. Time 0 on the abscissa indicates the end of the 1-min period during which Ringer's solution or 3-MPA was microinjected into the PnO. Asterisks (*) indicate significant differences from sleep deprivation. The hash symbol (\#) indicates significant differences from ad libitum sleep.



FIG. 7. All microinjection sites for experiments that measured nociception were localized to the pontine reticular nucleus, oral part $(\mathrm{PnO})$ and are represented by black dots on coronal brain stem plates (modified from Paxinos \& Watson, 2007). The numbers on the right side of each plate indicate the distance $(\mathrm{mm})$ from bregma. The vertical lines drawn on the sagittal schematic of the brain (Paxinos \& Watson, 2007) (top right) indicate the anterior and posterior range of coordinates for all microinjection sites. The digitized coronal section (bottom left) stained with Cresyl violet shows a representative microinjection site (arrow) in the PnO (Paxinos \& Watson, 2007).

revealed that propofol decreases GABA levels in the PnO. One implication of these data is that propofol causes loss of consciousness, in part, by decreasing extracellular GABA levels in the PnO. Manipulating GABA levels in the $\mathrm{PnO}$ altered nociception, and administering a GABA synthesis inhibitor into the PnO blocked the hyperalgesia caused by sleep deprivation. The results suggest that GABA in the PnO regulates nociception and mediates the hyperalgesia caused by sleep deprivation. The role of GABAergic transmission in the $\mathrm{PnO}$ in the regulation of anesthesia, sleep and pain is discussed in the following sections.

\section{Induction but not emergence is regulated by GABAergic transmission in the PnO}

Consistent with data from many laboratories demonstrating that GABAergic transmission in the PnO promotes wakefulness (Camacho-Arroyo et al., 1991; Xi et al., 1999; Sanford et al., 2003; Marks et al., 2008; Vanini et al., 2008, 2011; Watson et al., 2008, 2011; Brevig et al., 2010; Flint et al., 2010; Vanini \& Baghdoyan, 2013), the present data show that pharmacologically altering GABAergic transmission in the PnO modulates time to induction of general anesthesia. Microinjection of a GABA synthesis inhibitor (3-MPA) into the $\mathrm{PnO}$ decreased induction time by the inhaled anesthetic isoflurane (Vanini et al., 2008) and the intravenous anesthetic propofol (Fig. 3A). Microinjection of a GABA uptake inhibitor (NPA) into the $\mathrm{PnO}$ increased induction time by both isoflurane (Vanini et al., 2008) and propofol (Fig. 3B). In contrast, administration of GABA synthesis and uptake inhibitors into the $\mathrm{PnO}$ did not change the time to recovery from either isoflurane (Fig. 2) or propofol (Fig. 3C and D) anesthesia. Thus, the effects of 3-MPA and NPA on induction and emergence from anesthesia with the intravenous agent propofol paralleled the effects of these drugs on induction and emergence with the inhaled anesthetic isoflurane (Vanini et al., 2008). These data provide novel support for the conclusion that GABAergic transmission in the $\mathrm{PnO}$ regulates induction but not emergence from general anesthesia. The results are consistent with data that challenged the concept that emergence is the inverse process of the induction phase of anesthesia (Kelz et al., 2008). The lack of identity between the phases of induction and emergence is observed in flies, mice (Friedman et al., 2010) and now rats, indicating conservation across species.

Intravenous administration of propofol caused a significant decrease in extracellular GABA levels in the PnO (Fig. 3E and F). These data support the interpretation that changes in propofolinduced LoRR and RoRR are a function of changes in endogenous GABA levels in the PnO, and that one mechanism by which propofol causes loss of consciousness is by decreasing GABAergic transmission in the PnO. The mechanisms by which propofol decreases extracellular GABA levels remain incompletely understood. Propofol enhances GABAergic transmission at $\mathrm{GABA}_{\mathrm{A}}$ receptors (Bali \& Akabas, 2004) and can regulate neuronal GABA release (i.e. presynaptic inhibition) within the PnO. Extracellular glutamate levels in the PnO are greatest during wakefulness (Watson et al., 2011). Propofol decreases the release of glutamate and GABA, with a 
greater depression of glutamate release (Westphalen \& Hemmings, 2003). Thus, one potential mechanism by which propofol eliminates consciousness is, in part, by decreasing the excitatory/inhibitory transmitter ratio in the $\mathrm{PnO}$.

Additional support for the role of PnO GABA in regulating levels of arousal comes from studies of benzodiazepine site agonists. For example, administering the benzodiazepine site agonists zolpidem, diazepam and eszopiclone directly into the PnO caused drug-specific changes in cortical electroencephalographic activity and increased acetylcholine release in the PnO (Hambrecht-Wiedbusch et al., 2010). Systemic administration of eszopiclone to awake rats significantly decreased acetylcholine release in the $\mathrm{PnO}$ and increased electroencephalographic power in the delta frequency (HambrechtWiedbusch et al., 2010). These data suggest that different classes of clinically used sedative-hypnotics can exert their arousal-modulating effects by actions at $\mathrm{GABA}_{\mathrm{A}}$ receptors in the $\mathrm{PnO}$.

GABAergic input to the $\mathrm{PnO}$ arises from multiple sources. GABAergic neurons that project to the $\mathrm{PnO}$ are localized to the lateral hypothalamus (Boissard et al., 2003; Rodrigo-Angulo et al., 2008), amygdala (Boissard et al., 2003), periaqueductal gray (Boissard et al., 2003; Sapin et al., 2009) and pontine reticular formation (Liang \& Marks, 2009). Extracellular GABA originates from synaptic release (Mitchell \& Silver, 2000; Hamann et al., 2002; Houston et al., 2012), as well as non-synaptic release from neurons and glia (Timmerman \& Westerink, 1997; Watson et al., 2006; Angulo et al., 2008; Halassa et al., 2009).

Substantial data support the conclusion that 3-MPA decreases brain GABA levels. In vitro assays demonstrated that 3-MPA inhibits glutamic acid decarboxylase (Engel et al., 2001; Monnerie \& Le Roux, 2007). Whole-cell patch-clamp recordings from CA3 neurons showed that 3-MPA decreases the amplitude and frequency of GABAergic postsynaptic currents (Engel et al., 2001). Systemic administration of 3-MPA selectively decreases GABA levels measured in different forebrain, cerebellum and brain stem regions (Van der Heyden et al., 1979; Alsip et al., 1984; DiMicco \& Abshire, 1987; Kehr \& Ungerstedt, 1988; Toth \& Lajtha, 1988; Herbison et al., 1990; Alsip \& DiMicco, 1992; Timmerman et al., 1992; Varga \& Kunos, 1992). Microinjection or microdialysis delivery of 3-MPA to the caudate region (Toth \& Lajtha, 1988), medial preoptic area (Herbison et al., 1990) and substantia nigra (Van der Heyden et al., 1979) decreases GABA levels. Taken together, these studies support the conclusion that 3-MPA inhibits glutamic acid decarboxylase and reduces extracellular brain GABA levels by decreasing newly synthesized GABA.

Microinjection of the GABA uptake inhibitor NPA into the PnO during isoflurane (Vanini et al., 2008) or propofol (Fig. 3D) anesthesia did not significantly alter anesthesia recovery time. In view of evidence that general anesthesia decreases extracellular GABA levels in the PnO (Vanini et al., 2008), it could be argued that administration of NPA into the PnO during anesthesia does not alter endogenous GABA levels. Previously published data, however, demonstrate that delivery of NPA to the PnO during anesthesia increases extracellular GABA levels in the PnO (Watson et al., 2007; Vanini et al., 2008). Thus, there are now multiple lines of evidence to support the interpretation that increasing GABA levels in the $\mathrm{PnO}$ does not alter time to recovery from anesthesia.

\section{GABAergic transmission in the PnO modulates hyperalgesia caused by sleep deprivation}

The $\mathrm{PnO}$ is part of the ascending activating system that regulates sleep and wakefulness (Steriade \& McCarley, 2005; Brown et al., 2012), processes nociceptive information (Porro et al., 1991; Knight et al.,
2005; Ghazni et al., 2010), and coordinates autonomic and motor responses evoked by noxious stimuli (Price, 2000). Administering adenosine, acetylcholine, hypocretin and opioid receptor agonists into the PnO alters nociception (Kshatri et al., 1998; Tanase et al., 2002; Wang et al., 2009; Watson et al., 2010). The present results show that thermal nociception was decreased by a GABA synthesis inhibitor (Fig. 5A) and increased by a GABA uptake inhibitor (Fig. 5C) delivered to the PnO. These data support the conclusion that GABAergic transmission in the $\mathrm{PnO}$ also modulates nociception.

Injection of pentobarbital into rat mesopontine tegmentum causes analgesia, atonia and loss of consciousness (Devor \& Zalkind, 2001; Namjoshi et al., 2009). Pentobarbital enhances transmission at $\mathrm{GABA}_{\mathrm{A}}$ receptors. The brain stem area in which pentobarbital administration causes an anesthesia-like state (Devor \& Zalkind, 2001) is rostral and dorsal to the PnO region where GABA acts to promote wakefulness and increase nociception (Figs 4 and 7). These data further support the interpretation that the effects on arousal state and nociception brought about by activation of $\mathrm{GABA}_{\mathrm{A}}$ receptors vary as a function of brain region.

The finding that $4 \mathrm{~h}$ of total sleep deprivation increased thermal nociception (Fig. 6) is consistent with evidence from studies in humans showing that sleep disruption increases pain perception (Arima et al., 2001; Roehrs et al., 2006, 2012; Edwards et al., 2008). Hyperalgesia caused by sleep deprivation was decreased by administration of a GABA synthesis inhibitor into the PnO (Fig. 6). Nociceptive sensitivity varies as a function of arousal state (Callahan et al., 2008), and GABAergic transmission in the PnO regulates states of sleep and wakefulness (Vanini et al., 2011; Vanini \& Baghdoyan, 2013). After PnO microinjection of the GABA synthesis inhibitor 3MPA, PWL was measured when rats were awake. No measures were obtained when rats showed behavioral signs of sleep onset. Thus, changes in PWL were likely caused by inhibition of GABA synthesis within $\mathrm{PnO}$ networks that process nociceptive information (Fig. 7). The foregoing evidence supports the novel interpretation that GABAergic transmission within the $\mathrm{PnO}$ modulates nociception and mediates the increase in pain caused by sleep disruption. The present results encourage future studies designed to quantify the extent to which the results shown in Fig. 6 might reflect a net effect of hyperalgesia caused by sleep disruption and analgesia caused by 3-MPA.

Unconsciousness and analgesia are two clinical endpoints used to operationally define the state of anesthesia. How states of consciousness are generated (Miller, 2005) and how anesthetics work (Kennedy \& Norman, 2005; Brown et al., 2010) remain as major gaps in knowledge in anesthesiology and neuroscience. The data reported here help to bridge this gap by showing that GABAergic transmission in the $\mathrm{PnO}$ regulates the interacting states of wakefulness, sleep, anesthesia and pain.

\section{Limitations and conclusions}

An acknowledged limitation is that the present study did not determine whether the behavioral responses obtained after increasing or decreasing endogenous GABA can be attributed to the actions of GABA on one or a combination of $\mathrm{GABA}_{\mathrm{A}}$ and $\mathrm{GABA}_{\mathrm{B}}$ receptor subtypes. The present results encourage future studies using selective agonists and antagonists at $\mathrm{GABA}_{\mathrm{A}}$ and $\mathrm{GABA}_{\mathrm{B}}$ receptors in order to clarify the role of GABA receptor subtypes. Another limitation is that the neuronal networks by which GABA in the PnO regulates sleep, wakefulness and nociception remain incompletely understood. Future studies are needed to identify the neuronal networks that are inhibited by GABAergic mechanisms within the PnO to alter states of behavioral arousal and pain. 
The present results support the conclusions that GABA endogenous to the PnO promotes wakefulness (Vanini et al., 2008, 2011; Watson et al., 2008), and that induction and emergence from propofol anesthesia are not inverse processes (Kelz et al., 2008; Friedman et al., 2010). GABAergic transmission in the PnO regulates the time to loss of consciousness caused by propofol and isoflurane, but not time to recovery of consciousness. The results also indicate that hyperalgesia caused by sleep disruption is modulated by GABAergic transmission in the PnO. These data have translational relevance for sleep disorders medicine, as well as for anesthesiology. A persisting clinical problem is that sleep disruption worsens pain and pain medications disrupt sleep (Gauthier et al., 2011). The rational development of drugs with fewer side-effects will require data such as those presented here, that identify brain regions and neurotransmitter systems modulating altered states of consciousness, such as anesthesia, sleep and pain.

\section{Acknowledgements}

This study was supported by grants HL40881 (R.L.), HL65272 (R.L.) and MH45361 (H.A.B.) from the National Institutes of Health, Bethesda, MD, USA, and by the Department of Anesthesiology, University of Michigan, Ann Arbor, MI, USA. For expert assistance the authors thank Sha Jiang, Mary A. Norat and Melissa A. Teran from the Department of Anesthesiology, University of Michigan, Ann Arbor, MI, USA, and Kathy Welch, M.A., M.P.H. (Center for Statistical Consultation and Research, University of Michigan, USA).

\section{Abbreviations}

GABA, $\gamma$-aminobutyric acid; HPLC, high-performance liquid chromatography; LoRR, loss of righting response; 3-MPA, 3-mercaptopropionic acid; \%MPE, percentage of maximum possible effect; NPA, nipecotic acid; PnO, pontine reticular nucleus, oral part; PWL, paw withdrawal latency; RoRR, resumption of righting response.

\section{References}

Alkire, M.T., McReynolds, J.R., Hahn, E.L. \& Trivedi, A.N. (2007) Thalamic microinjection of nicotine reverses sevoflurane-induced loss of righting reflex in the rat. Anesthesiology, 107, 264-272.

Alsip, N.L. \& DiMicco, J.A. (1992) Time course of effects of 3-mercaptopropionic acid on GABA levels in different brain regions in guinea pigs: possible relationship with associated cardiovascular changes. Neurochem. Res., 17, 443-448.

Alsip, N.L., Simon, J.R., Fohl, L.D. \& DiMicco, J.A. (1984) Cardiovascular effects of 3-mercaptopropionic acid and levels of GABA in regions of the brain of guinea-pigs. Neuropharmacology, 23, 349-357.

Angulo, M.C., Le Meur, K., Kozlov, A.S., Charpak, S. \& Audinat, E. (2008) GABA, a forgotten gliotransmitter. Prog. Neurobiol., 86, 297-303.

Arima, T., Svensson, P., Rasmussen, C., Nielsen, K.D., Drewes, A.M. \& Arendt-Nielsen, L. (2001) The relationship between selective sleep deprivation, nocturnal jaw-muscle activity and pain in healthy men. J. Oral Rehabil., 28, 140-148.

Baghdoyan, H.A. \& Lydic, R. (2012) The neurochemistry of sleep and wakefulness. In Brady, S.T., Albers, R.W., Price, D.L. \& Siegel, G.J. (Eds), Basic Neurochemistry. Elsevier, New York, pp. 982-999.

Bali, M. \& Akabas, M.H. (2004) Defining the propofol binding site location on the $\mathrm{GABA}_{\mathrm{A}}$ receptor. Mol. Pharmacol., 65, 68-76.

Baracchi, F. \& Opp, M.R. (2008) Sleep-wake behavior and responses to sleep deprivation of mice lacking both interleukin-1 beta receptor 1 and tumor necrosis factor-alpha receptor 1. Brain Behav. Immun., 22, 982-993.

Boissard, R., Fort, P., Gervasoni, D., Barbagli, B. \& Luppi, P.H. (2003) Localization of the GABAergic and non-GABAergic neurons projecting to the sublaterodorsal nucleus and potentially gating paradoxical sleep onset. Eur. J. Neurosci., 18, 1627-1639.

Brevig, H.N., Watson, C.J., Lydic, R. \& Baghdoyan, H.A. (2010) Hypocretin and GABA interact in the pontine reticular formation to increase wakefulness. Sleep, 33, 1285-1293.

Brown, E.N., Lydic, R. \& Schiff, N.D. (2010) General anesthesia, sleep, and coma. New Engl. J. Med., 363, 2638-2650.
Brown, R.E., Basheer, R., McKenna, J.T., Strecker, R.E. \& McCarley, R.W. (2012) Control of sleep and wakefulness. Physiol. Rev., 92, 1087-1187.

Callahan, B.L., Gil, A.S., Levesque, A. \& Mogil, J.S. (2008) Modulation of mechanical and thermal nociceptive sensitivity in the laboratory mouse by behavioral state. J. Pain, 9, 174-184.

Camacho-Arroyo, I., Alvarado, R., Manjarrez, J. \& Tapia, R. (1991) Microinjections of muscimol and bicuculline into the pontine reticular formation modify the sleep-waking cycle in the rat. Neurosci. Lett., 129, 95-97.

Devor, M. \& Zalkind, V. (2001) Reversible analgesia, atonia, and loss of consciousness on bilateral intracerebral microinjection of pentobarbital. Pain, 94, 101-112.

DiMicco, J.A. \& Abshire, V.M. (1987) Evidence for GABAergic inhibition of a hypothalamic sympathoexcitatory mechanism in anesthetized rats. Brain Res., 402, 1-10.

Dutta, S., Matsumoto, Y., Gothgen, N.U. \& Ebling, W.F. (1997) Concentration-EEG effect relationship of propofol in rats. J. Pharm. Sci., 86, 37-43.

Edwards, R.R., Almeida, D.M., Klick, B., Haythornthwaite, J.A. \& Smith, M.T. (2008) Duration of sleep contributes to next-day pain report in the general population. Pain, 137, 202-207.

Engel, D., Pahner, I., Schulze, K., Frahm, C., Jarry, H., Ahnert-Hilger, G. \& Draguhn, A. (2001) Plasticity of rat central inhibitory synapses through GABA metabolism. J. Physiol., 535, 473-482.

Enna, S.J. \& McCarson, K.E. (2006) The role of GABA in the mediation and perception of pain. Adv. Pharmacol., 54, 1-27.

Flint, R.R., Chang, T., Lydic, R. \& Baghdoyan, H.A. (2010) GABA A $_{\text {recep- }}$ tors in the pontine reticular formation of $\mathrm{C} 57 \mathrm{BL} / 6 \mathrm{~J}$ mouse modulate neurochemical, electrographic, and behavioral phenotypes of wakefulness. J. Neurosci., 30, 12301-12309.

Franks, N.P. (2008) General anaesthesia: from molecular targets to neuronal pathways of sleep and arousal. Nat. Rev. Neurosci., 9, 370-386.

Friedman, E.B., Sun, Y., Moore, J.T., Hung, H.T., Meng, Q.C., Perera, P., Joiner, W.J., Thomas, S.A., Eckenhoff, R.G., Sehgal, A. \& Kelz, M.B. (2010) A conserved behavioral state barrier impedes transitions between anesthetic-induced unconsciousness and wakefulness: evidence for neural inertia. PLOS ONE, 5, e11903.

Gauthier, E.A., Guzick, S.E., Brummett, C.M., Baghdoyan, H.A. \& Lydic, R. (2011) Buprenorphine disrupts sleep and decreases adenosine concentrations in sleep-regulating brain regions of Sprague Dawley rat. Anesthesiology, 115, 743-753.

Ghazni, N.F., Cahill, C.M. \& Stroman, P.W. (2010) Tactile sensory and pain networks in the human spinal cord and brain stem mapped by means of functional MR imaging. Am. J. Neuroradiol., 31, 661-667.

Halassa, M.M., Fellin, T. \& Haydon, P.G. (2009) Tripartite synapses: roles for astrocytic purines in the control of synaptic physiology and behavior. Neuropharmacology, 57, 343-346.

Hamann, M., Rossi, D.J. \& Attwell, D. (2002) Tonic and spillover inhibition of granule cells control information flow through cerebellar cortex. Neuron, 33, 625-633.

Hambrecht-Wiedbusch, V.S., Gauthier, E.A., Baghdoyan, H.A. \& Lydic, R. (2010) Benzodiazepine receptor agonists cause drug-specific and state-specific alterations in EEG power and acetylcholine release in rat pontine reticular formation. Sleep, 33, 909-918.

Hargreaves, K., Dubner, R., Brown, F., Flores, C. \& Joris, J. (1988) A new and sensitive method for measuring thermal nociception in cutaneous hyperalgesia. Pain, 32, 77-88.

Hayes, R.L., Katayama, Y., Watkins, L.R. \& Becker, D.P. (1984) Bilateral lesions of the dorsolateral funiculus of the cat spinal cord: effects on basal nociceptive reflexes and nociceptive suppression produced by cholinergic activation of the pontine parabrachial region. Brain Res., 311, 267-280.

Herbison, A.E., Heavens, R.P. \& Dyer, R.G. (1990) Endogenous release of gamma-aminobutyric acid from the medial preoptic area measured by microdialysis in the anaesthetised rat. J. Neurochem., 55, 1617-1623.

Houston, C.M., McGee, T.P., Mackenzie, G., Troyano-Cuturi, K., Rodriguez, P.M., Kutsarova, E., Diamanti, E., Hosie, A.M., Franks, N.P. \& Brickley, S.G. (2012) Are extrasynaptic $\mathrm{GABA}_{\mathrm{A}}$ receptors important targets for sedative/hypnotic drugs? J. Neurosci., 32, 3887-3897.

Hudetz, A.G., Vizuete, J.A. \& Pillay, S. (2011) Differential effects of isoflurane on high-frequency and low-frequency gamma oscillations in the cerebral cortex and hippocampus in freely moving rats. Anesthesiology, 114, $588-595$.

Kehr, J. \& Ungerstedt, U. (1988) Fast HPLC estimation of gamma-aminobutyric acid in microdialysis perfusates: effect of nipecotic and 3-mercaptopropionic acids. J. Neurochem., 51, 1308-1310.

Kelz, M.B., Sun, Y., Chen, J., Cheng Meng, Q., Moore, J.T., Veasey, S.C., Dixon, S., Thornton, M., Funato, H. \& Yanagisawa, M. (2008) An 
essential role for orexins in emergence from general anesthesia. Proc. Natl. Acad. Sci. USA, 105, 1309-1314.

Kennedy, D. \& Norman, C. (2005) What don't we know? Science, 309, 75.

Knight, Y.E., Classey, J.D., Lasalandra, M.P., Akerman, S., Kowacs, F., Hoskin, K.L. \& Goadsby, P.J. (2005) Patterns of fos expression in the rostral medulla and caudal pons evoked by noxious craniovascular stimulation and periaqueductal gray stimulation in the cat. Brain Res., 1045, $1-11$.

Krogsgaard-Larsen, P. \& Johnston, G.A. (1975) Inhibition of GABA uptake in rat brain slices by nipecotic acid, various isoxazoles and related compounds. J. Neurochem., 25, 797-802.

Kshatri, A.M., Baghdoyan, H.A. \& Lydic, R. (1998) Cholinomimetics, but not morphine, increase antinociceptive behavior from pontine reticular regions regulating rapid-eye-movement sleep. Sleep, 21, 677-685.

Liang, C.L. \& Marks, G.A. (2009) A novel GABAergic afferent input to the pontine reticular formation: the mesopontine GABAergic column. Brain Res., 1297, 32-40.

Maneuf, Y.P., Gonzalez, M.I., Sutton, K.S., Chung, F.Z., Pinnock, R.D. \& Lee, K. (2003) Cellular and molecular action of the putative GABAmimetic, gabapentin. Cell. Mol. Life Sci., 60, 742-750.

Marks, G.A., Sachs, O.W. \& Birabil, C.G. (2008) Blockade of GABA, type A, receptors in the rat pontine reticular formation induces rapid eye movement sleep that is dependent upon the cholinergic system. Neuroscience, 156, 110 .

Miller, G. (2005) What is the biological basis of consciousness? Science, 309, 79.

Mitchell, S.J. \& Silver, R.A. (2000) GABA spillover from single inhibitory axons suppresses low-frequency excitatory transmission at the cerebellar glomerulus. J. Neurosci., 20, 8651-8658.

Monnerie, H. \& Le Roux, P.D. (2007) Reduced dendrite growth and altered glutamic acid decarboxylase (GAD) $65-$ and $67-\mathrm{kDa}$ isoform protein expression from mouse cortical GABAergic neurons following excitotoxic injury in vitro. Exp. Neurol., 205, 367-382.

Namjoshi, D.R., McErlane, S.A., Taepavarapruk, N. \& Soja, P.J. (2009) Network actions of pentobarbital in the rat mesopontine tegmentum on sensory inflow through the spinothalamic tract. J. Neurophysiol., 102, 700-713.

Nemanis, K., Vanini, G., Baghdoyan, H.A. \& Lydic, R. (2011) GABAergic transmission in Sprague-Dawley rat pontine reticular formation (PRF) modulates time required for the general anesthetic propofol to cause loss of wakefulness. SLEEP 34 (Abstr Suppl):0010, 2011. SLEEP Meeting, 2011. Minneapolis.

Paxinos, G. \& Watson, C. (2007) The Rat Brain in Stereotaxic Coordinates, 6th Edn. Academic Press, Burlington, MA.

Peterfi, Z., McGinty, D., Sarai, E. \& Szymusiak, R. (2010) Growth hormone-releasing hormone activates sleep regulatory neurons of the rat preoptic hypothalamus. Am. J. Physiol.-Reg. I., 298, R147-R156.

Porro, C.A., Cavazzuti, M., Galetti, A. \& Sassatelli, L. (1991) Functional activity mapping of the rat brainstem during formalin-induced noxious stimulation. Neuroscience, 41, 667-680.

Price, D.D. (2000) Psychological and neural mechanisms of the affective dimension of pain. Science, 288, 1769-1772.

Richey, S.M. \& Krystal, A.D. (2011) Pharmacological advances in the treatment of insomnia. Curr. Pharm. Design, 17, 1471-1475.

Robinson, T.E., Gorny, G., Mitton, E. \& Kolb, B. (2001) Cocaine selfadministration alters the morphology of dendrites and dendritic spines in the nucleus accumbens and neocortex. Synapse, 39, 257-266.

Rodrigo-Angulo, M.L., Heredero, S., Rodriguez-Veiga, E. \& Reinoso-Suarez, F. (2008) GABAergic and non-GABAergic thalamic, hypothalamic and basal forebrain projections to the ventral oral pontine reticular nucleus: their implication in REM sleep modulation. Brain Res., 1210, $116-125$.

Roehrs, T., Hyde, M., Blaisdell, B., Greenwald, M. \& Roth, T. (2006) Sleep loss and REM sleep loss are hyperalgesic. Sleep, 29, 145-151.

Roehrs, T.A., Harris, E., Randall, S. \& Roth, T. (2012) Pain sensitivity and recovery from mild chronic sleep loss. Sleep, 35, 1667-1672.

Sanford, L.D., Tang, X., Xiao, J., Ross, R.J. \& Morrison, A.R. (2003) GABAergic regulation of REM sleep in reticularis pontis oralis and caudalis in rats. J. Neurophysiol., 90, 938-945.

Sapin, E., Lapray, D., Berod, A., Goutagny, R., Leger, L., Ravassard, P., Clement, O., Hanriot, L., Fort, P. \& Luppi, P.H. (2009) Localization of the brainstem GABAergic neurons controlling paradoxical (REM) sleep. PLOS ONE, 4, e4272.

Steriade, M. \& McCarley, R.W. (2005) Brain Control of Wakefulness and Sleep. Kluwer Academic/Plenum Press, New York.
Tanase, D., Baghdoyan, H.A. \& Lydic, R. (2002) Microinjection of an adenosine A1 agonist into the medial pontine reticular formation increases tail flick latency to thermal stimulation. Anesthesiology, 97, 1597-1601.

Tassone, D.M., Boyce, E., Guyer, J. \& Nuzum, D. (2007) Pregabalin: a novel gamma-aminobutyric acid analogue in the treatment of neuropathic pain, partial-onset seizures, and anxiety disorders. Clin. Ther., 29, 26-48.

Timmerman, W. \& Westerink, B.H. (1997) Brain microdialysis of GABA and glutamate: what does it signify? Synapse, 27, 242-261.

Timmerman, W., Zwaveling, J. \& Westerink, B.H. (1992) Characterization of extracellular GABA in the substantia nigra reticulata by means of brain microdialysis. N.-S. Arch. Pharmacol., 345, 661-665.

Tobler, I. \& Jaggi, K. (1987) Sleep and EEG spectra in the Syrian hamster (Mesocricetus auratus) under baseline conditions and following sleep deprivation. J. Comp. Physiol. A., 161, 449-459.

Toth, E. \& Lajtha, A. (1988) 3-Mercaptopropionic acid administration into the caudate-putamen of the rat provokes dyskinesia. Pharmacol. Biochem. Be., 29, 525-528.

Tung, A., Herrera, S., Szafran, M.J., Kasza, K. \& Mendelson, W.B. (2005) Effect of sleep deprivation on righting reflex in the rat is partially reversed by administration of adenosine $\mathrm{A} 1$ and $\mathrm{A} 2$ receptor antagonists. Anesthesiology, 102, 1158-1164.

Van der Heyden, J.A., Venema, K. \& Korf, J. (1979) In vivo release of endogenous $\mathrm{GABA}$ from rat substantia nigra measured by a novel method. J. Neurochem., 32, 469-476.

Vanini, G. \& Baghdoyan, H.A. (2013) Extrasynaptic GABA $A$ receptors in rat pontine reticular formation increase wakefulness. Sleep, 36, 337-343.

Vanini, G. \& Nemanis, K. (2013) Nociception caused by sleep deprivation is reduced by decreasing GABA levels in rat pontine reticular formation. Sleep 36 (Abstr Suppl):0281, 2013. SLEEP Meeting, 2013. Baltimore.

Vanini, G., Torterolo, P., McGregor, R., Chase, M.H. \& Morales, F.R. (2007) GABAergic processes in the mesencephalic tegmentum modulate the occurrence of active (rapid eye movement) sleep in guinea pigs. Neuroscience, 145, 1157-1167.

Vanini, G., Watson, C.J., Lydic, R. \& Baghdoyan, H.A. (2008) Gamma-aminobutyric acid-mediated neurotransmission in the pontine reticular formation modulates hypnosis, immobility, and breathing during isoflurane anesthesia. Anesthesiology, 109, 978-988.

Vanini, G., Teran, M.A., Zhou, M., Baghdoyan, H.A. \& Lydic, R. (2009) GABAergic transmission in rat pontine reticular formation (PRF) does not modulate recovery time from isoflurane anesthesia. Society for Neuroscience Abstract Viewer/Itinerary Planner, Online: Program No. 375.13, 2009. 39th Annual Meeting, Chicago.

Vanini, G., Wathen, B.L., Lydic, R. \& Baghdoyan, H.A. (2011) Endogenous GABA levels in the pontine reticular formation are greater during wakefulness than during rapid eye movement sleep. J. Neurosci., 31, 2649-2656.

Vanini, G., Lydic, R. \& Baghdoyan, H.A. (2012) GABA-to-ACh ratio in basal forebrain and cerebral cortex varies significantly during sleep. Sleep. 35, 1325-1334.

Varga, K. \& Kunos, G. (1992) Inhibition of baroreflex bradycardia by ethanol involves both $\mathrm{GABA}_{\mathrm{A}}$ and $\mathrm{GABA}_{\mathrm{B}}$ receptors in the brainstem of the rat. Eur. J. Pharmacol., 214, 223-232.

Wang, W., Baghdoyan, H.A. \& Lydic, R. (2009) Leptin replacement restores supraspinal cholinergic antinociception in leptin-deficient obese mice. $J$. Pain, 10, 836-843.

Watson, C.J., Venton, B.J. \& Kennedy, R.T. (2006) In vivo measurements of neurotransmitters by microdialysis sampling. Anal. Chem., 78, 1391-1399.

Watson, C.J., Lydic, R. \& Baghdoyan, H.A. (2007) Sleep and GABA levels in the oral part of rat pontine reticular formation are decreased by local and systemic administration of morphine. Neuroscience, 144, 375-386.

Watson, C.J., Soto-Calderon, H., Lydic, R. \& Baghdoyan, H.A. (2008) Pontine reticular formation $(\mathrm{PnO})$ administration of hypocretin-1 increases PnO GABA levels and wakefulness. Sleep, 31, 453-464.

Watson, S.L., Watson, C.J., Baghdoyan, H.A. \& Lydic, R. (2010) Thermal nociception is decreased by hypocretin- 1 and an adenosine A1 receptor agonist microinjected into the pontine reticular formation of Sprague Dawley rat. J. Pain, 11, 535-544.

Watson, C.J., Lydic, R. \& Baghdoyan, H.A. (2011) Sleep duration varies as a function of glutamate and GABA in rat pontine reticular formation. $J$. Neurochem., 118, 571-580.

Westphalen, R.I. \& Hemmings, H.C. Jr. (2003) Selective depression by general anesthetics of glutamate versus GABA release from isolated cortical nerve terminals. J. Pharmacol. Exp. Ther., 304, 1188-1196.

Xi, M.C., Morales, F.R. \& Chase, M.H. (1999) Evidence that wakefulness and REM sleep are controlled by a GABAergic pontine mechanism. $J$. Neurophysiol., 82, 2015-2019. 